\title{
Os riscos do agir telecomunicacional ${ }^{1}$
}

\author{
The risks of telecommunicational acting \\ Los riesgos de la acción telecomunicacional
}

\author{
Pierre-Antoine Chardel \\ Institut Mines-Télécom Business School \\ <pierre-antoine.chardel@institut-telecom.fr>
}

Bernard Reber

CNRS/Sciences Po Paris

$<$ bernard.reber@sciencespo.fr>

\section{Resumo}

Este artigo pretende mostrar que, embora as "máquinas informacionais" reconfigurem em certos aspectos a comunicação interpessoal, a aparente fluidificação das relações não deixa de apresentar uma contrapartida de um ponto de vista hermenêutico, tampouco é isenta de certos riscos éticos relativos à evolução do senso de responsabilidade, à qualidade das trocas e ao respeito à autonomia das pessoas. Esses riscos da comunicação mediada por computador, mesmo não tão facilmente identificáveis e homogêneos, necessitam ser avaliados para além dos discursos e dos modos de representação que essas tecnologias apresentam e de acordo com os contextos nos quais estas se inscrevem.

Palavras-chave: Ética. Tecnologias da Informação. Comunicação.

\section{Abstract}

This article aims to show that if "information machines" re-configure the space of our interpersonal communication, the apparent fluidification of connections is not without hermeneutic consequences, as it involves certain ethical risks relating to the evolution of the feeling of responsibility, to the quality of exchanges and to the respect for individual autonomy. As the risks of computermediated communication are difficult to detect and not homogeneous, these technologies need to be evaluated beyond the discourse and the modes of representation that endorse them, and according to the contexts in which they are embedded.

Keywords: Ethic. Information Technologies. Communication.

\section{Resumen}

Este artículo pretende mostrar que, si bien las "máquinas de información" reconfiguran la comunicación interpersonal en ciertos aspectos, la aparente fluidificación de las relaciones no deja de presentar una contraparte desde el punto de vista hermenéutico, ni está exenta de ciertos riesgos éticos relacionados con la evolución. del sentido de responsabilidad, la calidad de los intercambios y el respeto a la autonomía de las personas. Estos riesgos de la comunicación mediada por ordenador, aunque no sean tan fácilmente identificables y homogéneos, necesitan ser evaluados más allá de los discursos y modos de representación que presentan estas tecnologías y según los contextos en los que se inscriben.

Palabras clave: Ética. Tecnologías de la información. Comunicación.

Se "o que reside nas máquinas é a realidade humana", ${ }^{2}$ as novas mediações informacionais (computadores, softwares, telas) interligadas por inúmeras formas de redes modificam

1 Uma versão preliminar deste artigo foi publicada em: Revue Communications, Volume 88, Issue 1, 2011, pages 149 to 157 . ISSN: 0588 8018. https://doi.org/10.3917/commu.088.0149. Traduzido por Denise Katchuian Dognini.

2 SIMONDON, Gilbert. Du mode d'existence des objets techniques. Paris: Aubier, 1989. p. 12. 
as formas de comunicação em nossa existência individual e coletiva. O computador oferece possibilidade de armazenamento e rapidez da gestão das informações que ultrapassam a capacidade da memória humana. Igualmente, a comunicação é posta em novas condições de instantaneidade. O filósofo dinamarquês Peter Kemp ressalta: a comunicação mediada por computador alarga ou substitui o que Kant denominava o entendimento humano, "isto é, a capacidade de operar com os conceitos no tempo e no espaço" . As condições de efetividade dessa operação à distância são novas, sem dúvida, mas também devem ser examinadas.

As "máquinas informacionais" ${ }^{4}$ de certa forma reconfiguram a comunicação com os outros. A aparente fluidificação das relações não deixa de apresentar uma contrapartida, tampouco é isenta de certos riscos éticos, tanto éticos como hermenêuticos. Estes não são facilmente identificáveis e homogêneos, de forma que são necessárias pesquisas sociotécnicas detalhadas - e muitas vezes interdisciplinares. ${ }^{5}$ De fato, a novidade anunciada nem sempre é facilmente avaliável e ultrapassa os discursos e os modos de representação que essas técnicas trazem consigo. Veremos que certas distinções entre informação e comunicação não se aplicam. Estamos diante de novas tecnologias de informação, ainda que alguns autores o questionem. ${ }^{6}$ Assim, examinaremos algumas modificações ontológicas da comunicação, as quais aumentam certos riscos éticos relativos à responsabilidade, ao respeito e à transparência.

\section{Tecnologias da informação e reconfigurações da comunicação}

O sentimento de poder originalmente associado às redes de computadores está ligado ao poder de tomar a palavra, ou melhor, de enviar suas palavras, sem os intermediários ou filtros das mídias tradicionais. As tecnologias da informação modificam essa assimetria e devolvem uma possibilidade de expressão e de reconquista de certa visibilidade social. Esses dispositivos informacionais são portadores de "novas formas de agir, ou ao menos uma dose extra de eficácia (por meio da interconexão e da força da organização em rede), [...] e podem contribuir significativamente [...] para a constituição de redes de alerta e de reflexão, ao enriquecimento do debate na ágora". . Podemos até mesmo dizer que os computadores são produtores de uma "transindividualização", termo empregado por Gilbert

\footnotetext{
3 KEMP, Peter. L'Irremplaçable. Une éthique de la technologie. Traduit de l'allemand par Pierre Rusch. Paris: Cerf, 1997. p. 218. 4 LYOTARD, Jean-François. La Condition postmoderne. Paris: Minuit, 1979. p. 12.

5 Ver, por exemplo, o projeto editorial interdisciplinar que reúne pesquisadores em ciências humans e sociais e em ciências da tecnologia da informação e da comunicação: REBER, Bernard; BROSSAUD, Claire (dir.). Humanités numériques. 1. Nouvelles technologies cognitives et épistémologie, et Humanités numériques 2. Socio-informatique et démocratie cognitive. Paris: Hermès Science International, 2007 (em inglês: Digital Cognitive Technologies, Wiley-ISTE, 2010).

6 JEANNERET, Yves. Y a-t-il (vraiment) des technologies de l'information? Québec: Presses Universitaires du Septentrion, 2000. Para as diferenças entre informação e comunicação, ver especialmente BOUGNOUX, Daniel. La Communication contre l'information. Paris: Hachette, 1995. Em contraponto, ver o dossiê de BROUSSEAU, Éric; MOATTY, Frédéric. Technologies de l'information et de la communication: approches croisées. Sciences de la société, n. 59, p. 3-35, 2003.

7 DAVID, Gérard. L'Enjeu démocratique des NTIC, Inventaire/Invention, 2001, p. 59. Ver igualmente CHAMBAT, Pierre. La démocratie assistée par ordinateur. Cahiers politiques, Paris, L'Harmattan, n. 4, p. 46-80, 2000.
} 
Simondon, ${ }^{8}$ que certamente não conhecia a internet, ${ }^{9}$ mas que propunha uma pertinente análise da relação entre ações individuais e mediação informacionais. No entanto, ainda é prematuro afirmar que a democracia é automaticamente mais "deliberativa". ${ }^{10}$ De um lado, essa atividade cognitiva e política é mais rica, ${ }^{11}$ de outro, a forma que a comunicação assume varia, caso seja ou não mediatizada pelas tecnologias informacionais. As condições de reflexividade e de compreensão mútua mudam. Tentaremos verificar em que medida se dão essas modificações.

Do ponto de vista existencial, e deixando de lado a superficialidade de certas lógicas comerciais, a comunicação é fundamental. É o que Karl Jaspers - bem antes de Habermas - nos convida a pensar: "Ser si mesmo [...], não é nada mais que ser incondicionalmente em comunicação. [...] O ser e o ser-em-comunicação são a mesma coisa”. ${ }^{12}$ A comunicação constitui o alicerce da existência individual e coletiva. Ela participa igualmente no reconhecimento. Contudo, o que falta em uma relação mediatizada pelo computador é o que Roman Jakobson denomina - nos termos de Malinovski - de a função "fática" da comunicação, que corresponde ao momento em que um sujeito deseja se assegurar da relação, independentemente do conteúdo da mensagem a ser transmitida: "Há mensagens que servem essencialmente para estabelecer, prolongar ou interromper a comunicação, para verificar se o circuito está funcionando ('Oi, você está me ouvindo?'), para chamar a atenção do interlocutor ou para me certificar de que ele não se distraia...". ${ }^{13}$

Ora, em uma situação de troca puramente eletrônica, a mensagem é enviada independentemente do conhecimento do contexto em que se encontra o interlocutor. ${ }^{14}$ Devemos observar, sem abraçar essa via de análise comparativa, que há mudanças próprias ao telefone, ao rádio ou à correspondência escrita. Os computadores não enxergam as condições de recepção e podem, nesse sentido, contribuir para que nós também nos tornemos insensíveis a elas. Insistindo sobre os quadros que determinam o ato de comunicação, os teóricos da Escola de Palo Alto destacaram aspectos relacionais essenciais a qualquer comunicação.

8 Cf. SIMONDON, Gilbert. L'Individuation psychique et collective. Préface de Bernard Stiegler. Paris: Aubier, 2007. Ver, em particular, a segunda parte.

9 Ele até confiava mais no rádio do que na televisão.

10 Cf. DAVID, Gérard. L'Enjeu démocratique des NTIC, op. cit., p. 59.

11 Para perceber isso, veja, por exemplo, a diferença que existe entre uma forma de deliberação auxiliada por computador proposta por Maxime Morge (Se concerter à l'aide d'un système multi-agents. In: REBER, Bernard; BROSSAUD, Claire (dir.). Humanités numériques 2, op. cit., p. 117-128) e as definições de deliberação na Retórica de Aristóteles - para tomar apenas essa referência tópica.

12 JASPERS, Karl. Raisons et Existence. Cinq Conférences. Première traduction en français par Robert Givord. Grenoble: Presses Universitaires de Grenoble, 1987, p. 80-81.

13 JAKOBSON, Roman. Essais de linguistique générale. Traduit de l'anglais et préfacé par Nicolas Ruwet. Paris: Minuit / Seuil, 1963, p. 217. Pode-se objetar, com base em certos trabalhos, que essa função continua. No entanto, é modificada quanto à eficácia e à qualidade da presença do outro ou de outros mediados pelo computador. 0 mesmo vale para o silêncio, que a função fática em situação de copresença tenta limitar. Veja em particular o trabalho de Judith Donath, como: Signals in Social Supernets. Journal of Computer-Mediated Communication, 13, 2007. Graças à teoria dos sinais em sociologia, derivada da economia e da biologia, ela lida com muitas outras coisas, como o jogo de identidades nas redes sociais apoiadas na Web $2.0 \mathrm{e}$ os riscos assumidos por alguns autores (cf. http://jcmc.indiana.edu/ vol13/issue1/donath.html). Ver, igualmente, TUFEKCl, Zeynep. Grooming, Gossip, Facebook and Myspace. Information, Communication \& Society, 11,2008 , p. 544-564.

14 Claro, essa dissociação é tão antiga quanto a escrita e a recepção de um texto transcontextual, mas aqui as condições temporais mudam qualitativamente. 
Toda comunicação pressupõe: (1) um aspecto físico-comportamental - uma comunicação não se limita a transmitir uma informação, mas induz um comportamento; ${ }^{15}$ (2) um aspecto hermenêutico - a percepção da intenção condiciona a boa e acertada decodificação da mensagem, seja verbal ou não verbal: "Atividade ou inatividade, palavra ou silêncio, tudo tem seu valor na mensagem". ${ }^{16}$ Ora, essas são as exatas condições "metacomunicacionais" que tendem a ser empobrecidas em uma comunicação à distância, na qual não se sabe com segurança o contexto em que se inserem os interlocutores.

Do ponto de vista da própria organização da sociedade, pode-se observar que a comunicação se inscreve em um horizonte de consenso. Karl-Otto Apel e Jürgen Habermas demonstram, a esse respeito, que toda legitimidade política supõe um consenso comunicacional que se fundamenta em uma situação preestabelecida. ${ }^{17} \mathrm{O}$ conceito de "agir comunicacional" permite que se formalize a natureza intrínseca intersubjetiva do pacto social, apoiando-se nas concepções de sociedade das grandes teorias sociais. ${ }^{18}$ A comunicação e a linguagem, portanto, contribuíram originariamente com uma função de integração social. Contudo, esses autores não ponderam as consequências das mudanças de mediações técnicas, que são consideráveis, uma vez que modificam as condições práticas de efetivação da comunicação. Além disso, a comunicação mediada por computador remete não somente ao relacionamento das máquinas entre si, mas também, e de forma mais intrínseca, a uma forma de sociedade. É exatamente o que notou Gilles Deleuze, ao explicar que a cada sociedade correspondem realidades maquínicas específicas: "As máquinas simples ou mecânicas para as sociedades de soberania, as máquinas energéticas para as de disciplina, as cibernéticas e os computadores para as sociedades de controle" ${ }^{19}$ Portanto, é necessário analisar os arranjos coletivos, dos quais as máquinas são apenas uma parte.

Em uma perspectiva sociológica, alguns autores sugeriram que a instantaneidade propiciada pelas máquinas poderia ser fonte de ansiedade para os usuários. ${ }^{20} \mathrm{~A}$ possibilidade de uma transmissão instantânea das mensagens reforça a necessidade de uma vigilância constante: "A espera de uma resposta anunciada ou aguardada gera (por vezes) comportamentos compulsivos [...] ainda que, como confessam os próprios informantes, a mensagem esperada não seja particularmente de grande importância”. ${ }^{21} \mathrm{O}$ risco, portanto, é de uma tirania da instantaneidade que pode prejudicar sobremaneira a qualidade das trocas. Ora, ainda que os computadores criem a ilusão de acelerar o tempo, uma vez que abreviam a duração de certas atividades, individuais, mas sobretudo as colaborativas, sempre haverá

15 WATZLAWICK, Paul; BEAVIN, Janet; JACKSON, Don. Une logique de la communication. Traduit de l'anglais (États-Unis) par Janine Morche. Paris: Seuil, 1972, p. 49.

16 Ibidem, p. 46.

$17 \mathrm{Cf}$. APEL, Karl-Otto. Éthique de la discussion. Traduit de l'allemand par Mark Hunyadi. Paris: Cerf, 1994.

18 Não retomaremos aqui a natureza problemática dessa hipótese.

19 DELEUZE, Gilles. Contrôle et devenir. Pourparlers, Paris, Minuit, 1990, p. 237.

20 Ver, sobre 0 assunto, 0 artigo de Luc Bonneville e Sylvie Grosjean: «À la recherche du temps virtuel" ou l'Homme confronté au désir et au devoir de vitesse. In: Reber, Bernard; Brossaud, Claire [dir.]. Humanités numériques 2, op. cit., p. 53-66.

21 DESPRES-LONNET, Marie et al. Le couple dispositif/pratique dans les échanges interpersonnels. In: SOUCHIER, Yves Jeanneret; LE MAREC, Joëlle (dir.). Lire, écrire, récrire. Objets, signes et pratiques des médias informatisés. Paris: Centre Pompidou, 2003, p. 215. 
uma duração necessária do ato de comunicação, que não se reduz a uma simples troca de informações. Essas mudanças ontológicas da comunicação, relacionadas às tecnologias da informação, podem acarretar certos riscos.

\section{Novos liames para novos desafios éticos}

A comunicação mediada por computador tanto pode dissimular os indivíduos como pode torná-los presentes e disponíveis. Ela esconde e desvela em um mesmo gesto. A esse respeito, surge o problema do anel de Giges, conforme formulado por Platão, em $A$ República: ${ }^{22}$ qual seria a ética de um ser humano portador de um anel que o tornasse invisível? Do ponto de vista de nosso sujeito, a questão poderia ser assim reformulada: poderíamos nos sentir também responsáveis por aquilo que dizemos à distância, sem interlocução direta?

As mediações eletrônicas transformam as vias de expressão dos conflitos e das tensões. Observem-se, a respeito, os fóruns de discussão: são em geral lugares em que a conversa pode se desenvolver livremente, podendo, por vezes, tornar-se abrupta. Em uma situação profissional, o desconhecimento de contextos de trabalho (um aeroporto, uma estação, um trem etc.) entre interlocutores afastados pode se tornar fonte de grande tensão. Geralmente, os interlocutores tendem a empregar mensagens curtas e rápidas, que podem ser mal interpretadas e mal recebidas: o empobrecimento da linguagem pode suscitar muitos equívocos e mal-entendidos; eles demonstram uma agressividade maior nesse tipo de relação do que demonstrariam de forma presencial. Assim, aquilo que nos reúne pelos novos meios informacionais é o mesmo que nos desvincula de certos "contratos" éticos.

O distanciamento, ou a relativa insensibilidade, pode dissolver nosso senso de responsabilidade. Em face da multiplicação de mediações, nem sempre somos capazes de apreender com clareza as consequências de nossos atos de linguagem. As formas de civilidade e a responsabilização são modificadas nas trocas interativas. ${ }^{23}$ É sempre mais fácil ser intransigente com um interlocutor por e-mail do que em sua presença. Isso vem de certa forma reforçar a tese formulada por Lévinas, segundo a qual o face a face tem algo de insubstituível na experiência do outro. É verdade que esse autor não tinha familiaridade com as novas tecnologias, mas suas intuições podem motivadamente nos alertar, pois ele defende com vigor a ideia de que o rosto marca o início da ética. Ao se dirigir ao outro, o usuário se expõe ao risco próprio à qualquer interlocução verdadeira: é essencialmente por meio da palavra viva que se estabelece a relação ética. ${ }^{24}$ Indiretamente, Lévinas nos alerta sobre o risco latente da perda dos rostos ou da proximidade imprescindível ao desenvolvimento de uma certa "consciência do outro". O eticista Peter Kemp, para quem toda técnica comporta implicitamente uma concepção do ser humano e das relações sociais, se inspirou em tal aviso:

22 PLATÃO. La République, II, 359c-360a. Traduit par Pierre Pachet. Paris: Gallimard, 1993, p. 99-100. Se pudéssemos ser injustos impunemente, como Giges, que tem esse anel que o torna invisível, agiríamos como ele. Platão, é claro, refuta essa hipocrisia.

23 Ver REBER, Bernard. Virtual Games Inviting Real Ethical Questions. In: DUBREUIL, Bertrand Hériard; GOUJON, Philippe (dir.). Technology and Ethics - A European Quest for Responsible Engineering. Louvain: Peeters, 2001, p. 121-132.

24 LEVINAS, Emmanuel. Totalité et Infini. Essai sur l'extériorité. Paris: Le Livre de Poche, 1992, p. 70. 
"Se nós nos encontrarmos somente mediante a interposição de telas, os outros serão apenas de imagens midiáticas, e não seres humanos pelos quais somos responsáveis”. ${ }^{25}$

\section{Algumas consequências éticas dessas reconfiguracões ontológicas}

Para além da problemática da distância que acabamos de mencionar, a comunicação mediada por computador poderia contribuir para que perdêssemos o sentido do verdadeiro encontro com o outro e do vagar de que ela necessita, aliás inerente a qualquer interação direta. Essa comunicação favorece uma racionalidade instrumental que tem precedência sobre uma racionalidade mais plenamente comunicacional. A desproporcionalidade entre a rapidez das ferramentas colaborativas e a lentidão da comunicação humana é tamanha que corremos o risco de querer impor mais celeridade e racionalidade às nossas trocas com o outro. Além disso, ainda que a desmaterialização das trocas permita que se estimulem formas benéficas de interatividade na vida social, também contribui para acentuar as contradições fortemente presentes no meio profissional. De fato, no mundo empresarial, onde se exige "daqueles que estão aptos ao combate performances sempre superiores em matéria de produtividade, de disponibilidade, de disciplina e de dedicação", ${ }^{26}$ os usos das ferramentas colaborativas são ambivalentes e capazes de provocar males bem específicos, relacionados diretamente a uma perda de autonomia. De toda forma, sejam quais forem os riscos associados à comunicação mediada por computador, a tecnologia tem em geral grande aceitação por parte dos empregados e de seus gerentes. ${ }^{27}$ Essa aceitação se fundamenta sobre o sentimento de que seria absurdo tentar se opor às tecnologias, na medida em que são uma expressão do desenvolvimento da história. De fato, muitas pessoas consideram legítimo o controle da comunicação por parte das empresas. Tal aceitação é certamente ligada ao fato de que a empresa já é um ambiente contratual que pressupõe a ideia de subordinação. ${ }^{28}$ No entanto, as recentes mutações do trabalho, relacionadas à evolução das tecnologias, sem dúvida precisam ser consideradas de forma mais ampla no que diz respeito à autonomia das pessoas e deveriam, por essa razão, suscitar uma apreciação dos problemas relacionados ao controle. ${ }^{29}$ Ora, se as tecnologias atuais permitem uma vigilância permanente (o exame de e-mails e de hábitos de navegação dos empregados, na internet, por exemplo), as exigências do trabalho em seu caráter contemporâneo impõem um respeito crescente à liberdade dos empregados. Hubert Bouchet, ex-vice-presidente da CNIL - Comissão Nacional de Informática e Liberdades, já expressou de maneira enfática as razões que deveriam motivar esse respeito: "fundamentalmente, sabe-se que o ser humano

25 KEMP, Peter. L'Irremplaçable, op. cit., p. 231. Tivemos a oportunidade de abordar esse problema em: CHARDEL, Pierre-Antoine; REBER, Bernard; KEMP, Peter (dir.). L'Éco-éthique de Tomonobu Imamichi. Paris: Éditions du Sandre, 2009.

26 DEJOURS, Christophe. Souffrance en France. La banalisation de l'injustice sociale. Paris: Seuil, 1998, p. 10.

27 Ver sobre essa questão: CHARDEL, Pierre-Antoine; ZORGBIBE, Guillaume; MAIGRON, Patrick. Les Technologies de la mobilité dans les organisations: une nouvelle source d'interrogation éthique. Rapport de recherche ETHICS, GET / Fondation Louis Le Prince Ringuet, 2006. 28 Jean-Pierre Le Goff: «A relação do trabalhador com a sua entidade patronal não é um vínculo de filiação nem de igualdade cívica, mas sim um contrato celebrado no âmbito de uma determinada atividade, trabalho, em comunidade produtora de bens e serviços». (Les Illusions du management. Pour le retour du bon sens, postface inédite de l'auteur, «Mal-être dans les organisations». Paris: La Découverte, 2000, p. 30). 29 BOUCHET, Hubert. Cybersurveillance dans l'entreprise. Terminal, n. 88, automne/hiver 2002-2003, p. 25. 
só opera graças à alternância de sombra e luz, portanto graças a uma opacidade necessária. [Porém] as tecnologias permitem que ele seja submetido permanentemente à luminosidade plena, o que acaba por impedi-lo de viver. A própria natureza nos ensina que os seres vivos não podem viver permanentemente sob plena luz" ${ }^{30}$ Naturalmente, sempre haverá uma lacuna entre as potencialidades tecnológicas do controle e sua eficácia. Na França, como em outros países da Europa, as formas de vigilância que se utilizam da informática estão enquadradas na lei. Todavia, os desdobramentos da tecnologia são atualmente tão sofisticados que se torna cada vez mais difícil avaliar os meios de vigilância à distância. $O$ fenômeno da convergência não nos permite distinguir o que diz respeito à vida profissional do que pertence à intimidade da vida privada: “o disco rígido do computador é igualmente ‘indiscreto’ em ambos os domínios”. ${ }^{31}$

Concluindo, insistiremos no fato de que, quais sejam as razões que possam justificar a expansão das novas tecnologias na sociedade e nas organizações, a comunicação humana jamais poderá evoluir nesse mesmo ritmo. As tecnologias comunicacionais e informacionais, das quais o computador participa, podem restringir, mas não devem jamais substituir a comunicação direta. Demonstramos aqui algumas dessas restrições ontológicas que podem acarretar riscos de diluição do sentido moral. Como uma provocação, diríamos que esses riscos não precisam anular os riscos reais da comunicação, tão acertadamente enfatizados por Karl Jaspers. A vontade de comunicar nunca significa "simplesmente submeter-se ao outro, mas conhecê-lo, escutá-lo [...] até admitir a necessidade de se transformar. [...] [Colocar-se] na situação em que me exponho ao risco". 32

Data do recebimento: $15 / 05 / 2021$

Data do aceite: 20/05/2021

Dados dos autores:

\section{Pierre-Antoine Chardel}

Doutor em filosofia e ciências sociais, orientador de pesquisas na Université de Paris (Faculté des SHS - Descartes), Pierre-Antoine Chardel é professor do IMT-BS (Institut Mines-Télécom Business School), membro do Institut Interdisciplinaire d'Anthropologie du Contemporain (IIAC, UMR 8177, CNRS / EHESS) e pesquisador convidado do MédiaLab da Sciences Po-Paris .É também professor na École des Hautes Etudes en Sciences Sociales (EHESS), onde coorganiza o seminário "Sociofilosofia da atualidade. Questões epistemológicas, metodológicas e críticas".

\section{Bernard Reber}

Prof. Bernard Reber é Diretor de Pesquisa do CNRS e membro do Centre de Recherches Politiques de Sciences Po. Filósofo moral e político, trabalha com problemas referentes à deliberação ética e democrática, sobre a inovação responsável, o pluralismo ético e científico. É coordenador de Ciências Humanas e Sociais do projeto multilíngue Encyclopédie.Sciences (ISTE, Londres), no qual também co-dirige o campo da Sociologia, ética e epistemologia da ciência. Ele dirige a coleção Interdisciplinaridade, Ciências e Humanidades, e codirige as coleções Inovação e Responsabilidade, Governança de Mudanças Globais.

\section{Ibidem.}

31 BOUCHET, Hubert. La Cybersurveillance sur les lieux de travail. Rapport adopté par la CNIL dans sa séance du 5 février 2002 , p. 18.

32 JASPERS, Karl. Raisons et Existence, op. cit., p. 87. 